DOI: $10.1515 / \mathrm{amm}-2017-0343$

\title{
SELECTING PARAMETERS FOR BENDING OF TUBES MADE OF THE X70 STEEL BY NUMERICAL MODELLING
}

\begin{abstract}
This paper addresses numerical analyses of the bending process for tubes made of the X70 steel used in gas distribution pipelines. The calculations performed under the research involved simulation of processes of tube bending with local induction heating. The purpose of these calculations was to establish process parameters making it possible to develop pipe bends of geometric features conforming with requirements of the applicable standards. While performing the calculations, an analysis was conducted to determine the probability of occurrence of folding and fractures according to the Cockcroft-Latham criterion.
\end{abstract}

Keywords: tube bending, numerical modelling, X70 steel, gas distribution pipelines

\section{Introduction}

There are numerous methods one can use for tube bending, and depending on the tube diameter, wall thickness, material grade and operating conditions of the final product, they may be divided into bending with heating and cold bending [1,2]. Utility properties of the product in question, namely a tube bend, are determined by the parameters of the tube bending process as well as of heat treatment. What is required of tube bends is that their strength parameters should be high, i.e. similar to those of non-deformed tube sections, and that their geometric features (wall thickness and cross section ovalisation) should conform with requirements of applicable standards [3-7].

While bending tubes, mainly those of large diameters and small bending radii, non-conventional bend forming methods are applied, involving local induction heating. This technology is relatively new (it was developed in 1980s), and so it has not been completely mastered and examined yet. Operating characteristics of bends produced by this method are mainly conditioned by appropriate choice of process parameters, i.e. temperature, rate and cooling conditions in the course of bending. The study in question comprised application of numerical modelling of tube bending with local induction heating for the sake of analysis of the effects of selected process parameters on the geometric features of the bends being produced, i.e. wall thickness in the tensioned and the compressed zone as well as the cross section ovalisation.

\section{Numerical modelling of the process of tube bending with local induction heating}

A diagram illustrating the process of tube bending with local induction heating has been provided in Fig. 1. In a bender, the tube is mounted in the tube pusher's clamping piece 1 . Under the impact of force $\mathrm{P}$, clamping piece 2 moves along the tube axis at pre-set velocity $\mathrm{v}$. The other tube end is attached to rotary forming arm 7 which forces the tube bending at required bending radius $R$. In the course of the bending process, the tube is locally heated by means of ring-shaped inductor 4 . As a result

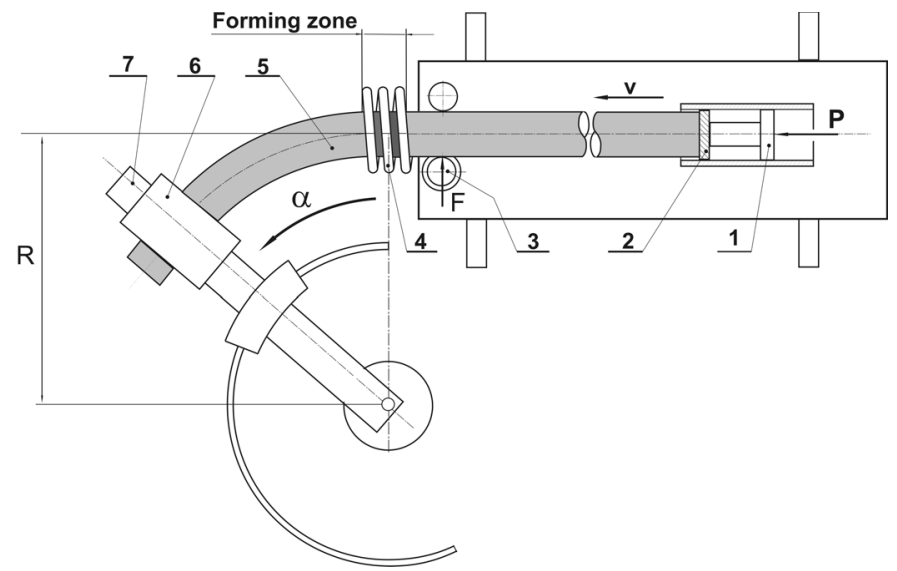

Fig. 1. Diagram of a tube bender with induction heating: $1-$ Tube pusher, 2 - Clamping piece, 3 - Guiding rollers, 4 - Inductor, 5 - Tube being bent, 6 - Mechanism for the tube end clamping, 7 - Forming arm, $\mathrm{P}$ - pushing force

\footnotetext{
* SILESIAN UNIVERSITY OF TECHNOLOGY, INSTITUE OF METALS TECHNOLOGY, KATOWICE, POLAND

** LUBLIN UNIVERSITY OF TECHNOLOGY, DEPARTMENT OF COMPUTER MODELLING AND METAL FORMING TECHNOLOGIES, POLAND 
of reducing the resistances to plastic flow of metal in the heating zone, local tube bending takes place and no further tube areas are plasticised [8-10].

The most significant parameters decisive of the bend's geometric features as well as of the bending process stability include: heating temperature, rate of tube travel and cooling conditions in the course of bending. Without access to a suitable database enabling the bending parameters to be defined, one which would be developed with reference to bends previously produced under industrial conditions, it is obligatory that test bends are made on pre-assumed process parameters. An optimum method enabling determination of these parameters is multivariant numerical modelling of the process. In the case addressed in the paper, tube bending with local induction heating was analysed by application of the finite element method, using version 12 of the Simufact Forming software package from MSC.Software. This software is used for numerical modelling of complex forming processes, and the results obtained by that means display high conformity with the relevant experience [8,10-12].

The numerical simulations were based on an assumption that the tube would be heated straight through a $40 \mathrm{~mm}$ section up to the forming temperature, and then cooled by water spraying outside the heating zone. The computational model comprised an assumed coefficient of heat exchange between the tube bend material and the environment equalling $2 \mathrm{~kW} / \mathrm{m}^{2} \mathrm{~K}$. The relevant calculations were conducted assuming an elastic-plastic material model dependent on temperature, developed on the basis of characteristics of deformation observed in the course of plastometric compression tests.

The model tests of the tube bending process were performed for a tube with the diameter of $D z=711 \mathrm{~mm}$, the wall thickness of $g=17.5 \mathrm{~mm}$ and the bending radius of $R=2133 \mathrm{~mm}$. The rate of travel was changed in the numerical calculations, and it would range between 10 and $40 \mathrm{~mm} / \mathrm{min}$. The overall range of the rate changes was established by relying on experience connected with industrial bending of tubes made of a material with similar chemical composition and a similar diameter, whereas the bending temperature was defined with reference to characteristics of technological plasticity of the X70 steel grade, as determined

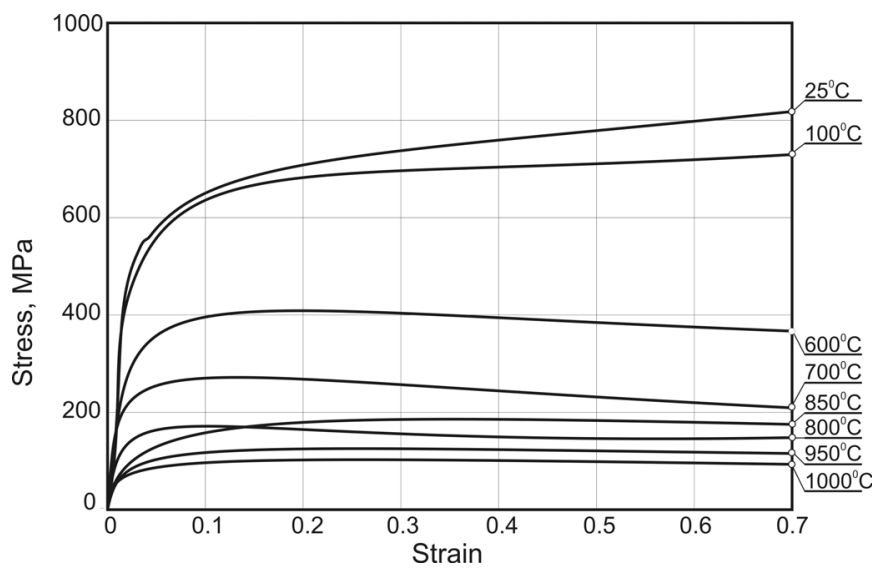

Fig. 2. Characteristics of deformability of steel grade X70 on deformation rate of $0.1 \mathrm{~s}^{-1}$ in plastometric tests using the Gleeble 3800 simulator. The tube bending temperature changes assumed for the sake of the numerical simulations ranged between 800 and $950^{\circ} \mathrm{C}$.

What the temperature range assumed for modelling also entailed was an optional impact of phase transition on the process of the material strengthening through deformation.

The tube bending process was numerically modelled for different values of the tube travel rate and the heating temperature from pre-assumed ranges of their variability. The calculations would also involve differentiation of temperature in the tube zone subject to tension and to compression in order that the process could proceed in a stable manner. Results of chosen computer simulations obtained for the parameters collated in Table 1 have been illustrated in Figs. 3,4 as well as in Table 2.

TABLE 1

Comparison of bending parameters for tubes made of the X70 steel for selected variants of numerical simulations

\begin{tabular}{|c|c|c|c|c|}
\hline \multirow{2}{*}{$\begin{array}{c}\text { Modelling } \\
\text { variant }\end{array}$} & \multicolumn{2}{|c|}{ Tube bending temperature, ${ }^{\circ} \mathrm{C}$} & \multirow{2}{*}{$\begin{array}{l}\text { Rate of } \\
\text { travel, } v \\
\mathrm{~mm} / \mathrm{min}\end{array}$} & \multirow{2}{*}{$\begin{array}{l}\text { Cooling } \\
\text { method }\end{array}$} \\
\hline & $\begin{array}{l}\text { Tensioned } \\
\text { zone }\end{array}$ & $\begin{array}{c}\text { Compressed } \\
\text { zone }\end{array}$ & & \\
\hline I & 850 & 840 & 12 & \multirow{3}{*}{$\begin{array}{l}\text { Forced } \\
\text { airflow }\end{array}$} \\
\hline II & 920 & 910 & 15 & \\
\hline III & 900 & 890 & 30 & \\
\hline
\end{tabular}

An analysis of the results obtained from the calculations implied that, irrespective of the simulation variant, one could observe inhomogeneous intensity of plastic strain of the tube bend being formed - higher in the compressed zone and lower in the tensioned zone. In the numerical calculations performed in accordance with the Cockcroft-Latham fracture criterion, the option of fractures occurring in the course of tube bending $[13,14]$ was analysed by following dependence (1).

$$
\int_{0}^{\varphi} \frac{\sigma_{1}}{\sigma_{i}} \geq C_{g r}
$$

where:

$\sigma_{1}-$ the highest principal stress,

$\sigma_{\mathrm{i}}-$ intensity of stress,

$\varphi-$ strain,

$C_{g r}$ - material constant established by experimental methods and considered as a required criterion

The aforementioned calculations evidenced that, for the tube bending parameters assumed, the integral reached the value of ca. 0.2. The foregoing means that there is no hazard of the tube bend fracturing while bending, since the critical value of parameter $C_{g r}$ on which the tube bend integrity may be compromised is $0.7 \div 1.0$. The geometric features of a tube bend being formed, established by application of FEM, depending on the bending variant assumed, have been compared in Table 2. The geometric features were measured in five cross sections, perpendicularly to the bending axis (Fig. 1). Regardless of the calculation variant, one could find the wall thickness to increase by a similar value in the compressed zone of the bend and to decrease in the 

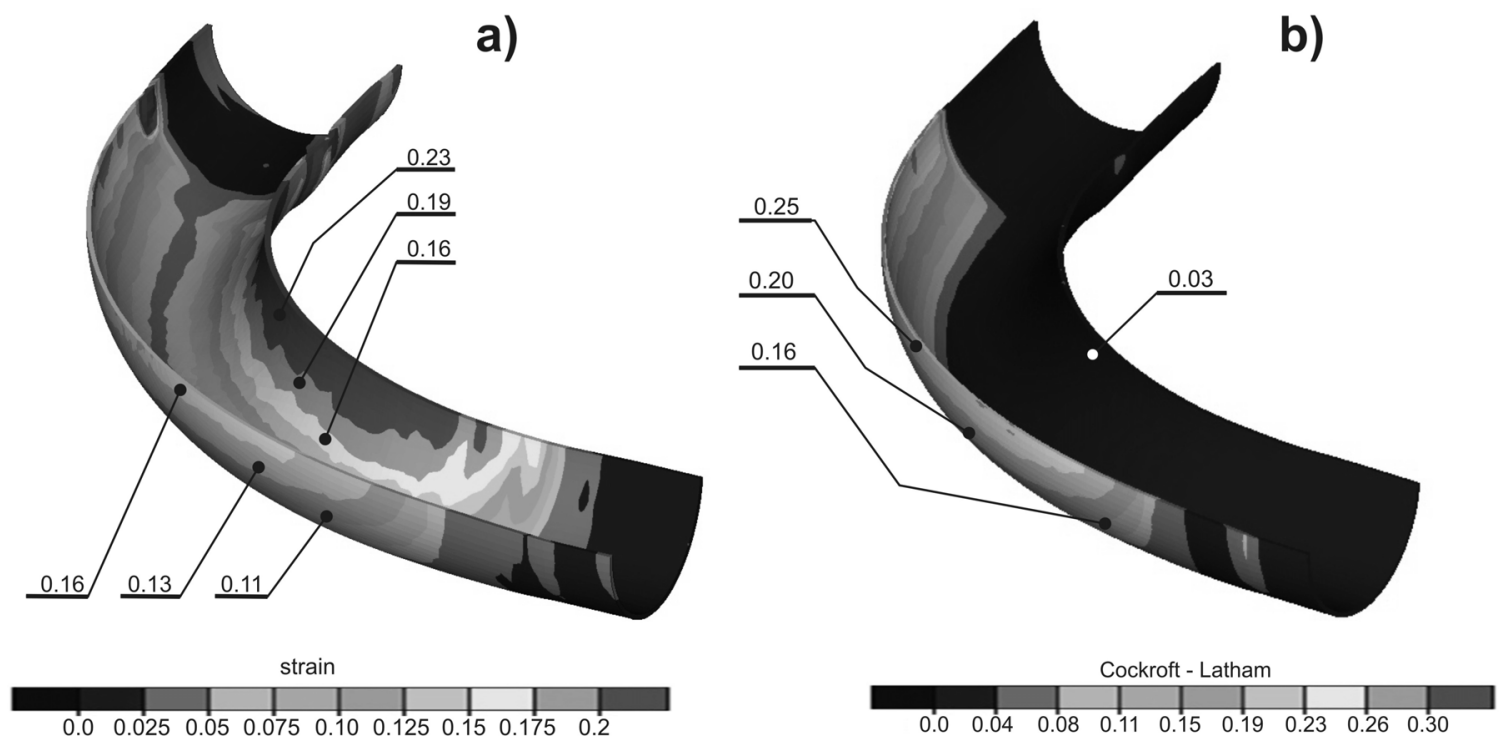

Fig. 3. Distribution of deformation intensity values (Fig. a) and the Cockcroft-Latham fracture criterion (Fig. b) on a tube bend cross section, as determined for bending variant II
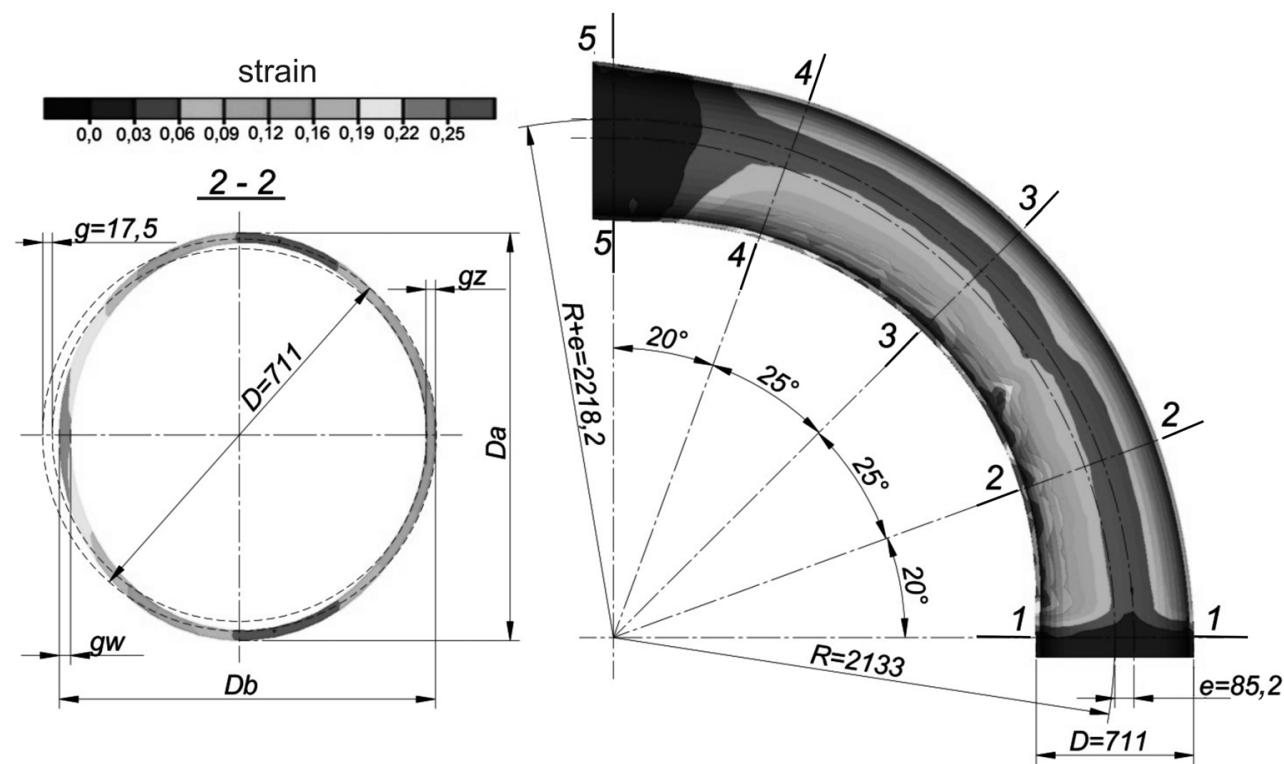

Fig. 4. Change of the tube cross section geometry in the bending zone determined by FEM

TABLE 2 zone subject to tension. What the simulations also revealed was

Bend geometric features established by FEM for selected modelling variants

\begin{tabular}{|c|c|c|c|c|c|}
\hline \multirow{2}{*}{$\begin{array}{c}\text { Modelling } \\
\text { variant }\end{array}$} & \multicolumn{2}{|c|}{$\begin{array}{c}\text { Mean wall } \\
\text { thickness, mm }\end{array}$} & \multicolumn{2}{|c|}{$\begin{array}{c}\text { Mean tube cross } \\
\text { section diameter, } \\
\text { mm }\end{array}$} & \multirow{2}{*}{$\begin{array}{r}\begin{array}{r}\text { Cross section } \\
\text { ovalisation, \% }\end{array} \\
e=\frac{2\left(D_{a}-D_{b}\right)}{D_{a}+D_{b}}\end{array}$} \\
\hline & $\begin{array}{l}\text { Com- } \\
\text { pressed } \\
\text { zone }\end{array}$ & $\begin{array}{c}\text { Ten- } \\
\text { sioned } \\
\text { zone }\end{array}$ & $D_{b}$ & $D_{a}$ & \\
\hline I & 20.9 & 16.7 & 729.5 & 679.4 & 7.1 \\
\hline II & 21.1 & 16.2 & 727.7 & 682.3 & 6.4 \\
\hline III & 20.8 & 16.8 & 738.5 & 669.4 & 9.7 \\
\hline $\begin{array}{l}\text { Standard } \\
\text { require- } \\
\text { ments [6] }\end{array}$ & 16 & 14 & - & - & 6.67 \\
\hline
\end{tabular}
a considerable impact of the bending parameters on the bend cross section ovalisation. A bend formed on the parameters corresponding to variant II showed ovalisation of $e=6.4 \%$, i.e. lower than the value of $e_{k}=6.67 \%$ considered as a criterion in the applicable standard, which had been assumed as a threshold for industrial applications. On the other hand, bending simulation variant I displayed the bend ovalisation being higher than the permissible value.

\section{Conclusions}

Research results indicate that there is a possibility for optimisation of local induction heating tube bending process on 
the basis of multi-option numerical simulations. Simulations include various kinematic and thermal parameters allowing for optimisation of bending rate, heating temperature and cooling conditions which ensure the achievement of desired geometrical features. Numerical modelling also allows the assessment process stability which can be measured using Concroft-Latham fracture criterion. Using this criterion it is possible to exclude process parameters that lead to rupture or buckling of the tube bend. Furthermore, numerical simulation procedure enables the optimisation of bending process by adjusting its parameters (feed speed and heating temperature) to minimise the cost of bend manufacturing.

Gathered data form numerical simulations were used under industrial conditions which enabled to minimise the costs associated with implementation without the need for corrections in bending parameters in industrial trials.

\section{Acknowledgements}

This work was supported by Association of Graduates of the Faculty of Metallurgy and Materials Engineering of Silesian University of Technology, Poland.

\section{REFERENCES}

[1] W. Kubiński, M. Kuczera, Obróbka Plastyczna Metali 4, 23-36 (2004).

[2] J. Pacanowski, Z. Kosowicz, Rudy i Metale Nieżelazne 41 (10), 419-423 (1996).

[3] M. Cieśla, K. Mutwil, G. Junak, Fatigue Failure and Fracture Mechanics XXVI: Proceedings of the XXVI Polish National Conference on Fatigue Failure and Fracture Mechanics, Source: AIP Conf. Proc. 1780, 020001 (2016).

[4] PN-EN 10216-2, Seamless steel tubes for pressure purposes.

[5] PN-EN 13480-3. Industrial metal pipelines. Design and calculations.

[6] PN-EN 12952-5, Water-tube boilers and auxiliary installations.

[7] PN-EN-ISO 3183, Petroleum and natural gas industries. Steel pipe for pipeline transportation systems.

[8] M. Cieśla, K. Mutwil, J. Tomczak, T.Kawała, Solid State Phenomena 246, 313-216 (2016).

[9] Z. Hu, J.Q.Li, Journal of Materials Processing Technology 91, 75-79 1999

[10] M. Cieśla, J. Tomczak, E. Hadasik, R. Findziński, T. Kawała, Hutnik, wiadomości hutnicze 81 (7), 487-491 (2014).

[11] J. Tomczak, Z. Pater, T. Bulazk, Archives of Civil and Mechanical Engineering 14 (1), 104-113 (2014).

[12] Z. Pater, J. Tomczak, J. Bartnicki, M.R. Lovell, P.L. Menezes, International Journal of Machine Tools \& Manufacture 67, 1-7 (2013).

[13] A. Stefanik, H. Dyja, S. Mróz, Archives of Metallurgy and Materials 56 (2), 545-549 (2011).

[14] A. Gontarz, J. Piesiak, Obróbka plastyczna metali XXI (4), (2010). 